\title{
Efficacy of Fixed-Dose Drugs in Treatment of Pulmonary Tuberculosis in Children
}

\author{
A. Starshinova ${ }^{1,2}$, U. Ovchinnikova ${ }^{1}$, I. Dovgaluk ${ }^{1}$ and Yablonskiy ${ }^{1,2}$ \\ 1. Saint Petersburg Research Institute of Phthisiopulmonology, Ligovskiy av.2-4, St.-Petersburg 191036, Russian Federation \\ 2. Saint Petersburg State University, 21st line of V.O., 8a, Saint-Petersburg 199106, Russian Federation
}

\begin{abstract}
The main problem in treatment of children with various forms of tuberculosis is the lack of pediatric dosages of anti-TB drugs. The aim of the study is to determine efficacy of the <Isoniazid $150 \mathrm{mg}+$ Pyrazinamid $375 \mathrm{mg}+$ Rifampicin $150 \mathrm{mg}>$ (Ftizamax ${ }^{\circledR}$ ) fixed-dose combination. We estimated the clinical, radiological and laboratory parameters during treatment of 73 children with pulmonary tuberculosis, of which 34 children were treated by the <Isoniazid 150 mg+Pyrazinamid 375 mg+Rifampicin $150 \mathrm{mg}>$ in combination with the Ethambutol; while the others were treated with mono-drugs under the standard regimen I. Effective use of <Isoniazid $150 \mathrm{mg}+$ Pyrazinamid $375 \mathrm{mg}+$ Rifampicin $150 \mathrm{mg}>$ (Ftizamax ${ }^{\circledR}$ ) for children is supported by positive results towards the end of the intensive phase of the therapy and the continuation phase, as well as by minimized adverse drug reactions during treatment. Combination of active substances in the drug and its dosage is easy to use, which allows recommending this drug for treatment of tuberculosis in children.
\end{abstract}

Key words: Children, tuberculosis, treatment, fix-dose drugs.

\section{Introduction}

Developing and wider introduction of new forms of multi-compound anti-TB drugs increase opportunities of antibacterial therapy. Combined anti-TB drugs can be used in treatment of patients with TB in accordance with regimens of chemotherapy and daily dosage of drugs [1-4]. Combined anti-TB drugs provide effective drug interaction, prevent development of drug resistance by TB bacteria as a result of mono-therapy, optimize controlled treatment, and improve cost-effectiveness by better organization of patients' care [5-8]. The value of administration of combined anti-TB drugs with fixed doses in prevention of drug resistance of TB bacteria and reducing clinical errors has been proved. Combined drugs are non-inferior by activity to constituent compounds at their separate administration, but ensure more reliable control of drug intake compliance, reduce risk of overdose, and

Corresponding author: Anna Starshinova, DMedSci, MD, Ph.D, research fields: tuberculosis, treatment, immunology, pediatrics. convenient in use [9-13].

National phthisiopediatric turned out to new conditions of its functioning. These conditions demand serious correction of anti-TB measures among children and teenagers with development of scientifically-grounded methods of prophylaxis, early diagnosis and treatment of TB [12]. The main problem in treatment of children with different occurrence of TB infection is an absence of pediatric dosage of anti -TB drugs, while $80 \%$ of children under 7 years old who need treatment have weight not exceeding $20 \mathrm{~kg}$ [11]. Given the difficulties experienced in realization of therapy, developing and administration of drug formulations as combined drugs with pediatric dosages is an actual goal. It will help to simplify methods of drug administration and to decrease psychoemotional and exercise stress when taking a lot of drugs.

The purpose of the study is determined efficacy of combined drug formulation <isoniazid 150 mg+pyrazinamidum 375 mg+rifampicin $150 \mathrm{mg}>$ in treatment of respiratory tuberculosis in children. 


\section{Materials and Methods}

A prospective, clinical, cohort study was carried out to study efficacy of anti-TB therapy among 73 children who were under medical treatment at department of children's phthisiology "Saint-Petersburg Research Institute of Phthisiopulmonology" of Ministry of healthcare of Russia from 2014 to 2016. Before beginning of therapy and during treatment (ending intensive phase of therapy, 6 months of therapy) all children received the full range of medical examinations, including: a plan radiography of chest, computed tomography, Diaskintest, methods of etiologic diagnosis, including BACTECMGIT 960, RT-PCR, determination of drug resistance of TB bacteria to anti-TB agents. According to study purpose all patients were divided into 2 groups. In Group I ( $\mathrm{n}=34)$, children received combined drug formulation <isoniazid 150 mg+pyrazinamidum 375 mg+rifampicin 150 mg> in complex with ethambutol. In Group II $(\mathrm{n}=39)$ children received therapy by isoniazid, pyrazinamidum, rifampicin, ethambutol taking into account age-specific dosage variances for these drugs.

The main inclusion criteria in the study were: age from 3 to 14 years old; newly diagnosed patients with lung TB; absence of bacterial excretion with multi-drug resistant and extensively drug-resistant MBT (Mycobacterium tuberculosis); absence of contact with a person with bacterial excretion with multi-drug resistant or extensively drug-resistant MBT; the use of standard scheme of therapy.

Exclusion criteria: patients with extra pulmonary localization of TB; children with body weight less than $7 \mathrm{~kg}$; bacterial excretion of multi-drug resistant or extensively drug-resistant MBT; idiosyncrasy to drugs.

In structure of clinical forms in both groups of children the dominated form was TB of intrathoracic lymph: 28 (82.4\%) and 33 (84.6\%) respectively. Tuberculous primary complex was observed in less number of cases-6 (17.6\%) in Group I, and 6 (15.4\%) in Group II. In phase of infiltration specific process was identified among 5 children (14.7\%) in Group I and among 4 children (10.4\%) in Group II. In phase of calcination-among 29 (85.3\%) in Group I and among 35 (89.7\%) in Group II respectively. In majority of cases 27 (79.4\%) and 30 (76.9\%) in both groups there was complicated course of the disease (bronchopulmonary damage, TB bronchi, pleuritis, destruction of lung tissue). In 2 children from Group I and in 1 child from Group II MBT was identified by sowing method BACTEC MGIT 960: sensitivity remains to all drugs.

In the scheme of therapy combined drug formulation <isoniazid $150 \mathrm{mg}+$ pyrazinamidum 375 mg+rifampicin 150 mg> (Ftizamax $\left.{ }^{\circledR}\right)$ (combined drug international non-proprietary name dispersible tablet №84; product license Macleods Pharmaceuticals Ltd, LP 001810-270812, 2012), and ethambutol were used.

Groups were comparable according to clinical and $\mathrm{X}$-ray and laboratory data. Therapy was carried out according to existing standard-setting documents. Statistical processing of the results was carried out with assistance of Microsoft Office World Excel 2007, with the use of non-parametric methods, and also criteria $\chi^{2}$ with Yates correction. Differences were significant when $p<0.05$.

\section{Results and Discussion}

Evaluation of clinic and roentgenologic data by the end of 2 months of intensive phase of therapy in I and II monitoring groups are shown in Fig. 1.

According to presented data among children who received combined drug <isoniazid 150 mg+pyrazinamidum 375 mg+rifampicin $150 \mathrm{mg}>$ in scheme of anti-TB therapy symptoms of intoxication at early stage disappeared statistically more frequent (79.4\% in comparison with $46.2 \%, \chi^{2}=8.49, p<0.01$ ) (see in Fig. 1): improving well-being, appetite, emotional tonus, absence of low-grade fever, improving body weight from 1.5 to $3.0 \mathrm{~kg}$. According to Diaskintest statistically higher there was reduction of 


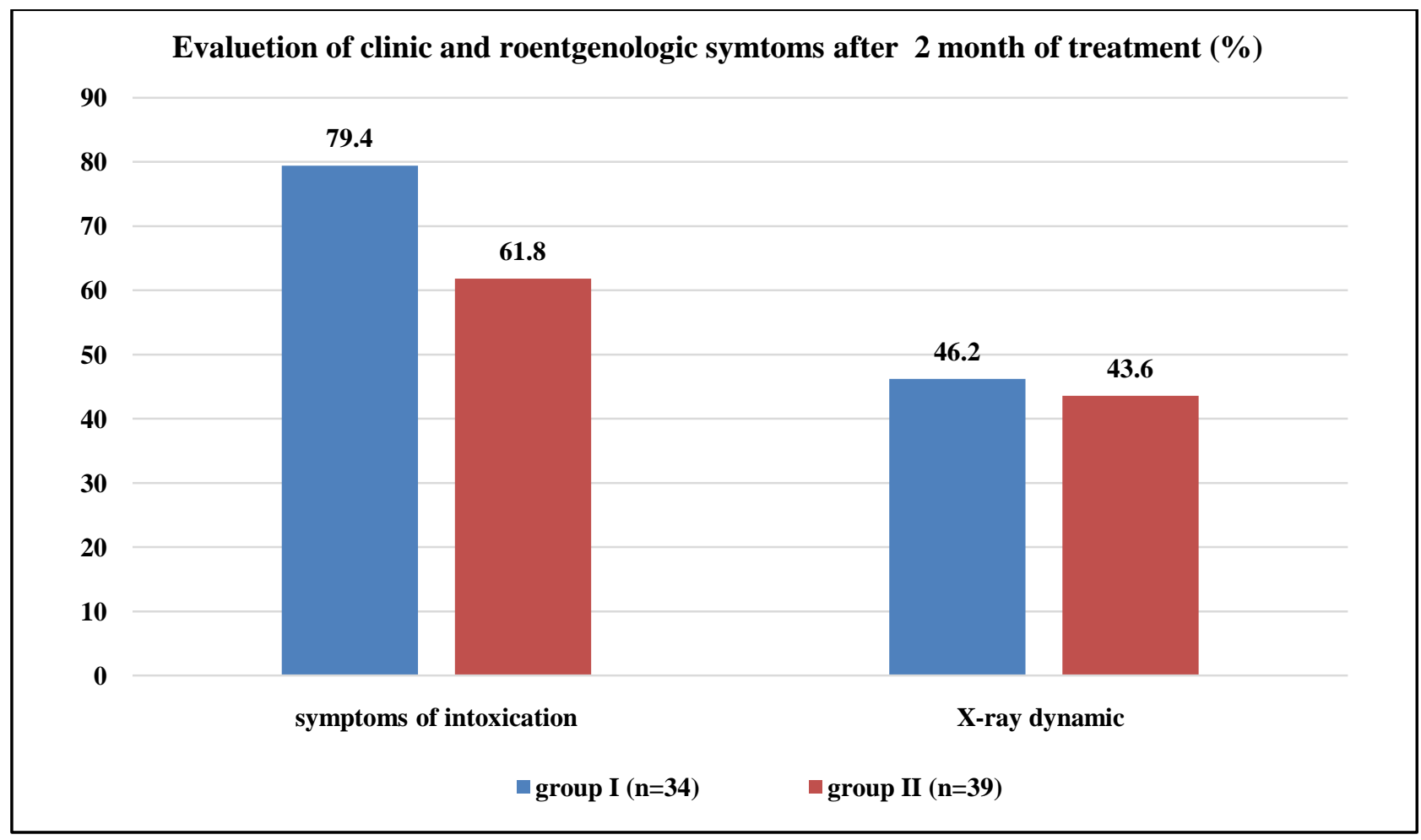

Fig. 1 Evaluation of clinic and roentgenologic symptoms after 2 months of treatment (\%).

tuberculosis infection activity in Group I (64.7\% against $41.0 \%, \chi^{2}=4.08, p<0.05$ ), while size of papule did not differ greatly among children in both groups both before treatment and at the end of intensive phase $(17.9 \pm 1.1 \mathrm{~mm}$ and $16.8 \pm 0.9$ in Group I; $18.1 \pm 1.2 \mathrm{~mm}$ and $17.3 \pm 1.1 \mathrm{~mm}$ in Group II). Significant differences between groups in X-ray dynamic at treatment phase were not observed. Cessation of bacterial excretion was achieved to the end of intensive phase of therapy among all children.

Against the background of extension phase of therapy by the end of 6 months completed comparison of treatment efficacy among children with the use of combined drug <isoniazid $150 \mathrm{mg}+$ pyrazinamidum $375 \mathrm{mg}+$ rifampicin $150 \mathrm{mg}>$ and children who received therapy with the use of drugs in standard scheme of therapy showed the absence of toxic syndrome nearly among all patients (see in Fig. 2).

X-ray dynamic was considered as positive (by multi-layer spiral CT of thorax) statistically more frequent among patients in Group I (85.3\% against
64.1\%, where $\left.\chi^{2}=4.24, p<0.05\right)$. There was significant decrease in inflammatory changes in intrathoracic lymph nodes, their size, induration, in many cases-calcification, and also resorption of infiltration in pulmonary tissue. All patients in both groups demonstrated cavity closure by 6 months of therapy. Significant differences between groups during period of therapy were observed by Diaskintest. Children who received combined drug <isoniazid 150 mg+pyrazinamidum 375 mg+rifampicin 150 mg> demonstrated considerable decrease in activity of TB infection (88.2\% against $61.5 \%$, where $\chi^{2}=6.72 p<$ 0.01 ). In such case it should be noted that diameter of papule among patient of Group I in 6 months of treatment was less than among children in Group II ( $9.1 \pm 1.7 \mathrm{~mm}$ against $14.3 \pm 1.2 \mathrm{~mm}$ ).

Incidence of adverse drug reactions against the background of therapy among children from Groups I and II is shown in Fig. 3. Hepatotoxic reactions were most common and registered statistically more frequently when receiving mono-drugs (38.5\% against 


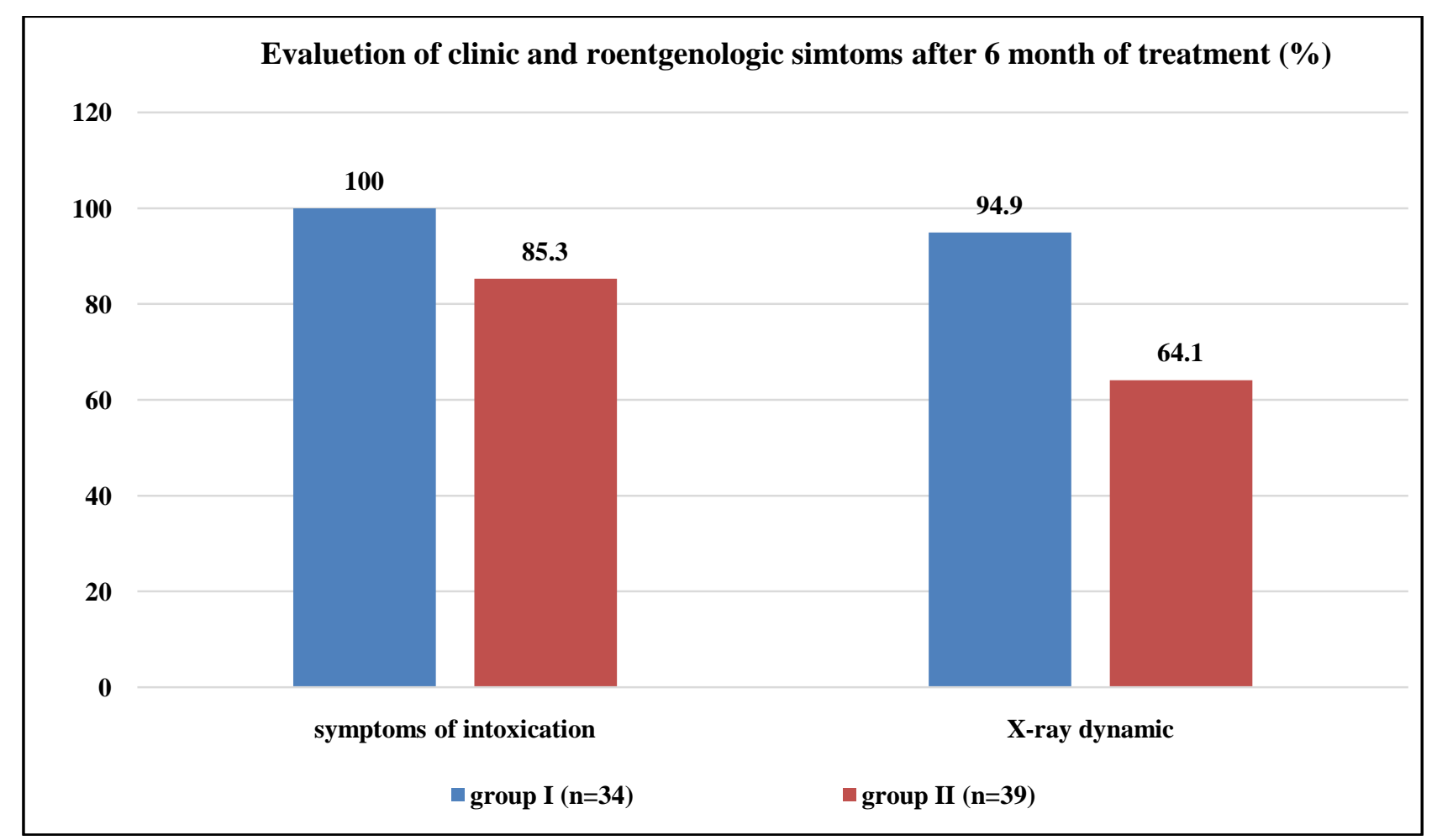

Fig. 2 Evaluation of clinic and roentgenologic symptoms after 6 months of treatment (\%).

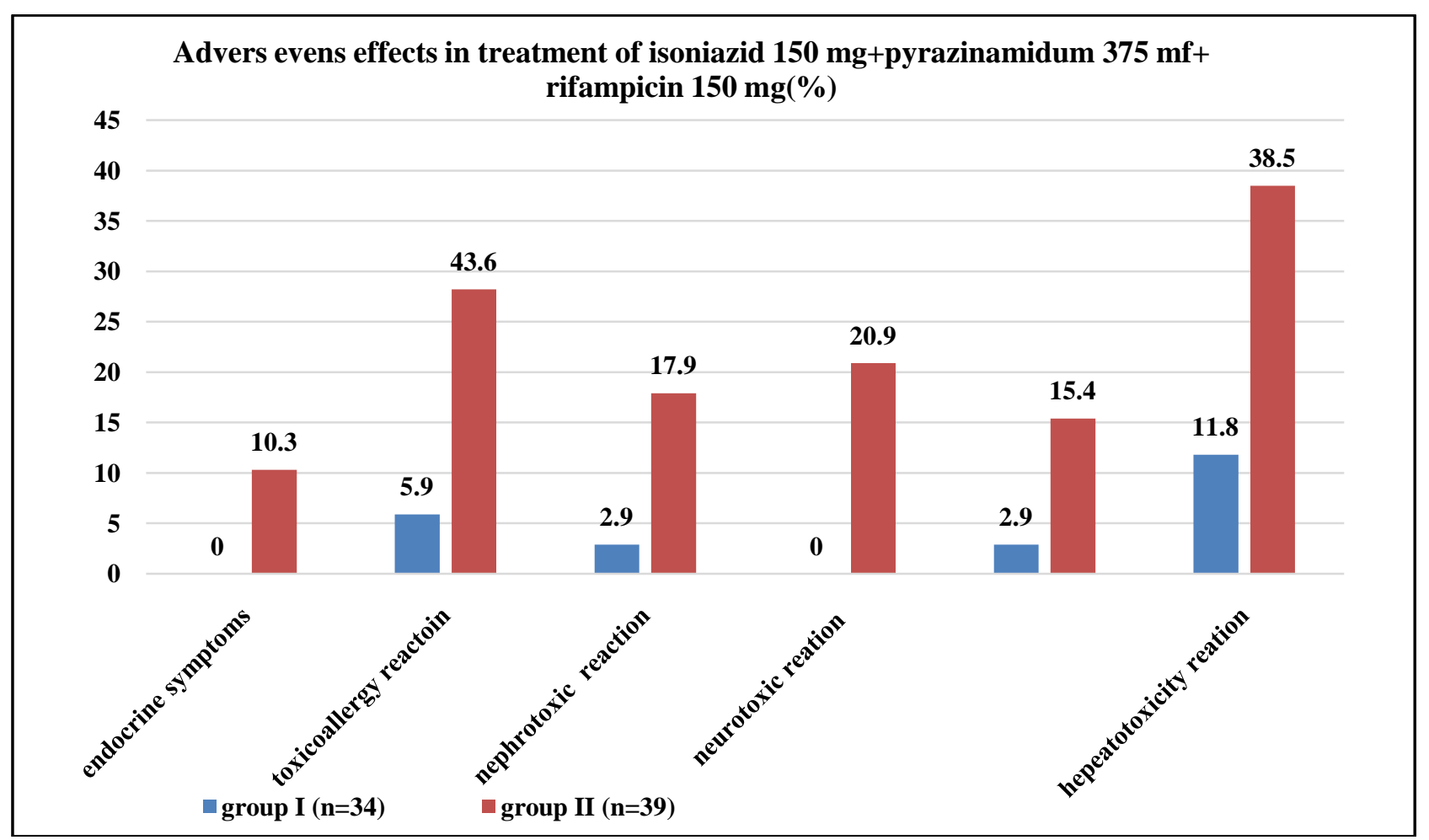

Fig. 3 Adverse evens effects in treatment of isoniazid $150 \mathrm{mg}+$ pyrazinamidum $375 \mathrm{mg}+$ rifampicin $150 \mathrm{mg}$ (\%). 
$11.8 \%, \chi^{2}=6.72 p<0.01$ ), as well as toxico-allergic manifestations (28.2\% and 5.9\%, $\left.\chi^{2}=6.18 p<0.05\right)$ and nephrotoxic $\left(17.9 \%\right.$ and $\left.2.9 \%, \chi^{2}=4.19 p<0.05\right)$. Neurotoxic manifestations in the form of hyperexcitability, attention failure, behaviour modification -8 (20.9\%), and also endocrinological disorders-4 (10.3\%), against the background of treatment, were registered only among children of Group II. There were no non-recoverable adverse effects for the use of combined drug <isoniazid 150 mg+pyrazinamidum 375 mg+rifampicin 150 mg>. There were non-recoverable adverse drug reactions against the background of receiving preparations among 5 children of Group II in the form of developing toxic drug-induced hepatitis with persistent laboratory abnormalities that required permanent discontinuation of anti-TB drugs and administration of detoxication therapy.

\section{Conclusion}

Conducted study showed high therapeutic efficacy of combined drug <isoniazid $150 \mathrm{mg}+$ pyrazinamidum $375 \mathrm{mg}+$ rifampicin $150 \mathrm{mg}>$ in treatment of TB of respiratory system among children. When including the drug in scheme of therapy intoxication symptoms disappeared among majority of children by the end of intensive phase (79.4\%), substantial reductions of TB infection activity according to Diaskintest (64.7\%).

Against the background of extension phase of therapy by the end of 6 months efficacy of treatment of children was estimated by significantly positive dynamic at X-ray examination (multi-layer spiral CT of chest) that was observed statistically more frequently among patients with the use of combined drug-isoniazid $150 \quad \mathrm{mg}+$ pyrazinamidum 375 mg+rifampicin $150 \mathrm{mg}$ (Ftizamax) (85.3\%). It was also observed that there was significant decrease of inflammatory changes in intrathoracic lymph nodes, their size, induration, in many cases - calcification, and also the resorption of infiltration changes in pulmonary tissue, cavity closure among all patients.
The use of combined drug-isoniazid 150 mg+pyrazinamidum 375 mg+rifampicin $150 \mathrm{mg}$ (Ftizamax) allowed minimizing developing of adverse drug reactions, as these reactions (hepatotoxic. toxico-allergic manifestations, nephrotoxic) were registered statistically more frequently among children who received anti-TB mono-drugs. There were no non-recoverable adverse drug reactions at the use of Ftizamax. Results of the study demonstrate that combination of drug substances in combined drug formulation has high clinical efficiency and safety, serves a reliable method of controlled therapy, doses are convenient for use that allows to recommend this drug in TB treatment among children.

\section{References}

[1] Zuev, A. P., Mokhireva, L. V., Urchenko, N. I., Mishin, V. U., Sterlikov, S. A., and Russkih, O. E., 2012. "Clinical Efficacy and Safety of Combined Drugs with Fixed-Dose Phthizoetham B6 and PhthizopiramB6 When Treatment Newly Diagnosed of Lung TB Patients with Mycobacterium Excretion.” (Туберкулез и болезнилегких) J. Tuberculosis and Lung Disease 5: 44-52.

[2] Dovgaluk I. F. 2013. “A New Method of TB Diagnosis of Respiratory among Children.” (Медицинскийальянс) Medical Alliance 2: 43-9.

[3] Dovgalyuk, I. F., and Korneva, N. V. 2011. "Clinical and Epidemiological Features of Tuberculosis in Children of North-West of the Russian Federation.” (Туберкулез и болезнилегких) J. Tuberculosis and Lung Disease 3: 12-6.

[4] Companion Handbook to the WHO Guidelines for the Programmatic Management of Drug-Resistant Tuberculosis. 2014 World Health Organization, p. 448.

[5] Kildusheva E.U. and others. 2012. "Combined Drug Isopask in Complex Treatment of TB Patients with Multiple Resistance of Causative Microorganism.” (Фтизиатрияипульмонология) Phthisiology and Pulmonology 1 (8): 29-34.

[6] Kulikov, A. U., Sorokovikov, I. V., Mokhireva, L. V., and Mohirev, A. V. 2012. "Pharmacoepidemiological Research of Administration of Combined Anti-TB Drug with Fixed-Dose Phtizoethamum B6 at Complex Treatment of TB Patients.” (Туберкулез и болезнилегких) J. Tuberculosis and Lung Disease 10: 41-6.

[7] Mokhireva, L. V., Khoseva, E. N., Karkach, O. O., 
Mokhirev, A. V., Jura, P. I., and Morozova, T. E. 2011. "Pharmacoepidemiological Research of Reproducible Combined Anti-TB Drugs and Commitment to Them of Phthisio-therapists in Wide Clinical Practice.” (Биомедицина) Biomedicine 3: 141-8.

[8] Lienhardt, C., et al. 2011. "Efficacy and Safety of a 4-Drug Fixed-Dose Combination Regimen Compared with Separate Drugs for Treatment of Pulmonary Tuberculosis: The Study C Randomized Controlled Trial.” JAMA 305 (14): 1415-23.

[9] "Guidelines on TB Treatment among Children for National Programs of Fighting against TB.” Second edition. Chapter 2 (WHO/HTM/TB 2010, 13).

[10] Sterlikov, S., Rudnev, S. G., and Sterlikova, S. S. 2015. "Effectiveness of Children Treatment with Lung TB
(Results of 2 Years Observation).” (Туберкулез и болезнилегких) J. Tuberculosis and Lung Disease 93 (9): 24-6.

[11] Aksenova, V. A. and others. 2015. "Federal Clinical Recommendations for Diagnosis and Treatment of Respiratory TB among Children.” (Медицинскийальянс) Medical Dlliance 3: 10-23.

[12] Bangalore, S., Kamalakkannan, G., Parkar, S., and Messerli, F. 2007. "Fixed-Dose Combinations Improve Medication Compliance: A Meta-analysis.” American Journal of Medicine 120 (8): 713-9.

[13] Monedero, I., and Caminero, J. A. 2011. "Evidence for Promoting Fixed-Dose Combination Drugs in Tuberculosis Treatment and Control: A Review.” Int. J. Tuberc. Lung Dis. 15 (4): 433-9. 